\title{
$\beta$-Amino Acids: Role in Human Biology and Medicinal Chemistry - A Review
}

Nagina Naveed Riaz ${ }^{1,2^{\star}}$, Fazal-ur-Rehman $\mathbf{M}^{1}$ and Muhammad Mahboob Ahmad ${ }^{2}$

${ }^{1}$ Chemistry Department, University of Education, Lahore-Vehari Campus, Punjab, Pakistan

${ }^{2}$ Institute of Chemical Sciences, Bahaudin Zakariya University, Multan, Punjab, Pakistan

\begin{abstract}
$\beta$-amino acids are an important class of macromolecules. They play role in life for survival. $\beta$-amino acids gained significant interest due to their interesting pharmaceutical uses as hypoglycemic, antiketogenic characteristics, sterile and antifungal activities, anthelminthic as well as potent insecticidal characteristics. These are vital building blocks for the preparation of pharmaceutical and agrochemical target molecules. These are utilized in development of drugs, bimolecular structure and molecular recognition. They are also important in treatment of different diseases which are viral to human health. They play important role in regulation of nutritional metabolism and immunity. It has also led to their wider adoption as intermediates in new drugs and has been a focus of considerable attention in medicinal chemistry. $\beta$-amino acids have found extensive applications as components of biologically active peptides and small molecule pharmaceuticals. Synthetic derivatives of biologically relevant peptides incorporating $\beta$-amino acids often display interesting pharmacological activity, with increased potency and enzymatic stability. $\beta$-peptides participate in arrangement of incredible stable auxiliary structures. This review summarizes recent developments about the different roles of $\beta$-amino acids in human biology and some implications in medicinal chemistry.
\end{abstract}

Keywords: $\beta$-Amino acids; Antiketogenic; Pharmacological; Therapeutic; Immunohistochemical; Arrhythmogenesis

\section{Introduction}

$\beta$-amino acids gained significant interest due to their remarkable pharmaceutical uses as hypoglycemic, antiketogenic characteristics, sterile and antifungal activities, anthelminthic as well as potent insecticidal characteristics [1-3]. These are vital building blocks for the preparation of pharmaceutical and agrochemical target molecules [4]. These are utilized in development of drugs, bimolecular structure and molecular recognition [5].

$\beta$-amino acids have found extensive applications as components of biologically active peptides and small molecule pharmaceuticals. Synthetic derivatives of biologically relevant peptides incorporating $\beta$-amino acids often display interesting pharmacological activity, with increased potency and enzymatic stability. $\beta$-peptides participate in arrangement of incredible stable auxiliary structures [6]. $\beta$-peptides are extremely steady biomolecules against in vitro and in vivo proteolytic degradation. They were utilized to prepare antibiotics such as magainins that was exceptionally strong but it was not easy to utilize it as simple drugs due to degradation by proteolytic enzymes in bodies $[7,8]$. Most of amino acids and derivatives of beta family of amino acids are discussed in this review.

\section{Taurine}

An amino acid that is totally different from other famous families of amino acids is Taurine (Figure 1) that has sulphonic group instead of carboxylic group. Human liver cells synthesize the Taurine from cysteine and methionine. It is a polyvalent $\beta$-amino acid. It also has most significant activities. It is also called as Anti-oxidant and membrane stabilizer. Taurine has numerous therapeutic applications in curing of AIDS, growth, diabetes, congestive heart failure, athletic wounds, interstitial cystitis, wretchedness, fibromyalgia and joint pain. Taurine is likewise critical in reestablishing the kidney lessened gluthathione (GSH) material and GSH peroxidase activities and furthermore to diminish the platinum gathering and MDA creation in kidney. Taurine additionally opposes against cisplatin-induced histopathalogical shifts inside kidneys [9-11].

\section{Transforming growth factor}

Transforming growth factor beta (TGF- $\beta$ ) (Figure 2) has several profibrogenic, anti- immunosuppressive and inflammatory effects. The stability of these activities is required for maintaining tissue homeostasis. Both, (TGF- $\beta$ ) excess and deficiency are causal for the development of fibrotic and autoimmune liver diseases respectively which can be inhibited by anti-(TGF- $\beta$ ) treatments like neutralizing antibodies. In the liver, (TGF- $\beta$ ) is a very potent profibrogenic mediator of cellular responses leading to tissue repair, ECM production, growth regulation, and apoptosis [12].

\section{Amyloid- $\beta$ peptide}

Amyloid- $\beta$ peptide $(A \beta)$ interrelates with vasculature to sway $A \beta$

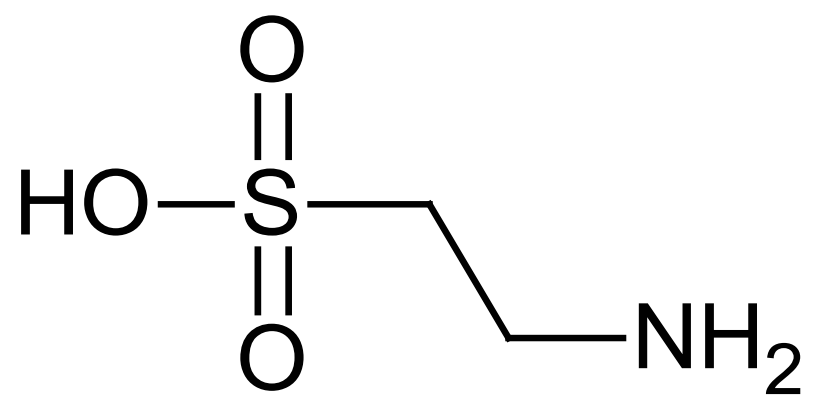

Figure 1: Taurine.

*Corresponding author: Nagina Naveed Riaz, PhD Scholar, Institute of Chemical Sciences, Bahaudin Zakariya University (BZU), Multan, Punjab, Pakistan, Tel: +923347201261; E-mail: naginanaveed@ue.edu.pk

Received September 06, 2017; Accepted October 09, 2017; Published Octobe 16,2017

Citation: Riaz NN, Rehman F, Ahmad MM (2017) B-Amino Acids: Role in Human Biology and Medicinal Chemistry - A Review. Med Chem 7: 302-307. doi: 10.4172/2161-0444.1000472

Copyright: ( 2017 Riaz NN, et al. This is an open-access article distributed unde the terms of the Creative Commons Attribution License, which permits unrestricted use, distribution, and reproduction in any medium, provided the original author and source are credited. 
<smiles>O=C(CCOc1ccc2c(-c3c(-c4ccccn4)nn4c3CCC4)ccnc2c1)OCCN1CCOCC1</smiles>

stages in cerebral blood flow and brain, and provides a way of increasing the $A \beta$-induced cellular stress underlying neuronal dysfunction and dementia (Figure 3). Deposition of Amyloid- $\beta$ peptide $(A \beta)$ in the central nervous system (CNS) is enhanced in Alzheimer disease. $A \beta$ is neurotoxic and brings oxidant stress in the endothelial cells [13]. Alzheimer's disease (AD) is characterized by synaptic and axonal deterioration along with the neurofibrillary tangles and $\beta$-amyloid supplies entitled senile plaques. The $\beta$-amyloid peptides $\left(A \beta_{(1-40)}, A \beta_{(1-}\right.$ ${ }_{42}$ ) of 40-42 amino acid lengths are the chief components of the amyloid deposits [14].

\section{$\beta$-defensins}

Antimicrobial peptides are relatively small molecules, less than 100 amino acids, which have a broad spectrum of antimicrobial activity. They serve as an ancient defense mechanism against pathogenic microorganisms that can easily come interact with the host through the environment. These molecules are considered as part of the innate immune system of all species. Avian antimicrobial peptides are one of them. They are also known as $\beta$-defensins. Defensins-cysteine-rich antimicrobial peptides are with a triple-stranded $\beta$-sheet structure. Most defensins have showed antimicrobial activity (Figure 4) against a wide range of pathogens including bacteria and fungi [15].

\section{$\beta$-Amino amides}

A novel arrangement of $\beta$-amino amides consolidating melded heterocycles, i.e., triazolopiperazines, were orchestrated and assessed as inhibitors of dipeptidyl peptidase IV (DPP-IV) for the treatment of diabetes type 2. Recently, the incretin hormone Glucagon like Peptide-1 (GLP-1) (Figure 5) has been utilized to cure the type 2 diabetes. This peptide hormone is released from the gut in response to food intake. GLP-1 has a clearly well-known part in glucose homeostasis through stimulus of insulin biosynthesis and excretion, and embarrassment of glucagon release. Prominently, GLP-1 normalizes the insulin in a rigorously glucose-dependent manner. Thus, GLP-1 therapy can pose either little risk or no risk of hypoglycemia. Other known impact of GLP-1 therapy comprises the decelerating gastric discharging and reduction of appetite. Active GLP-1 (GLP-1[7-36] amide) is quickly ruined in vivo through the action of dipeptidyl peptidase IV (DPPIV), a serine protease which splits a dipeptide from the N-terminus to give the inactive GLP-1[9-36] amide. Therefore, a small-molecule inhibitor of (DPP-IV) would rise the half-life of active GLP-1 and extend the beneficial effects of this incretin hormone. (2R)-4-Oxo-4[3-(trifluoromethyl)-5,6-dihydro[1,2,4] triazolo[4,3-a]pyrazin-7(8H)yl]-1-(2,4,5-trifluorophenyl)butan-2-amine is a powerful, vocally active (DPP-IV) inhibitor with excellent selectivity above the other prolineselective peptidases [16].

\section{Fascins}

Fascins are evolutionarily conserved actin-binding proteins that are existing in both invertebrate and vertebrate animals. Fascins are C.493 amino acid polypeptides that are distinctive in sequence from all other actin-bundling proteins. Sequence pattern analysis and a crystal structure of fascin-1 exposed that fascins are members of the beta-trefoil fold family of proteins and fascins contain four beta- trefoil domains of amino acids. Recent data from several laboratories have indicated that fascin is up-regulated in several human carcinomas (Figure 6) and in individual tissues, correlates with the clinical violence of tumors and poor patient survival. The identification of biomarkers to offer more effective initial diagnosis of potentially violent tumors, or identify tumors liable to targeted therapies, is an important aim in clinical research [17].

\section{Estrogen}

Estrogen and its receptor (ER) play important roles in the genesis

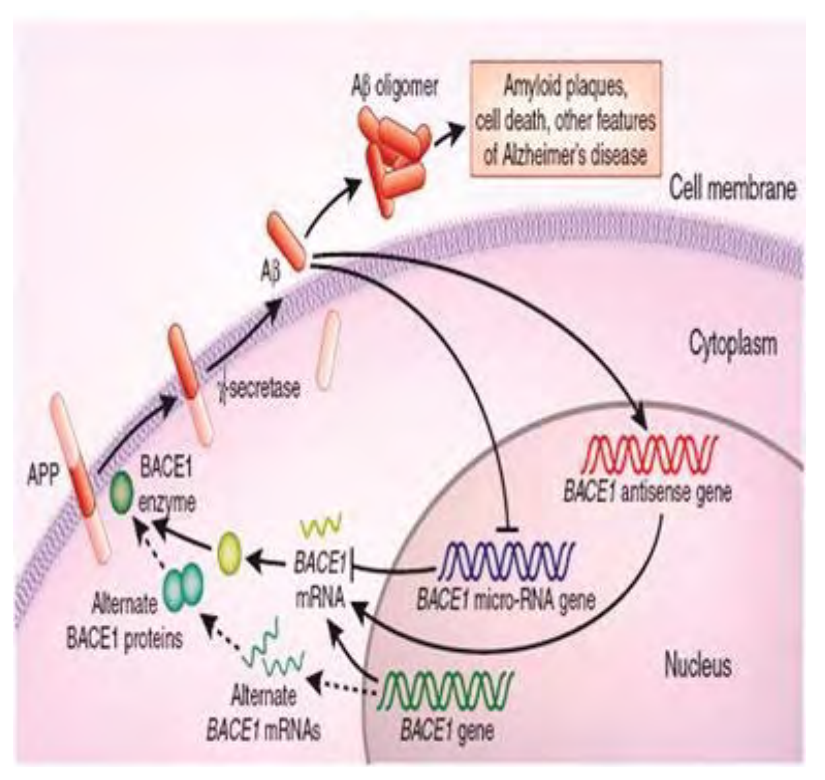

Figure 3: Amyloid- $\beta$ peptide $(A \beta)$ interactions.

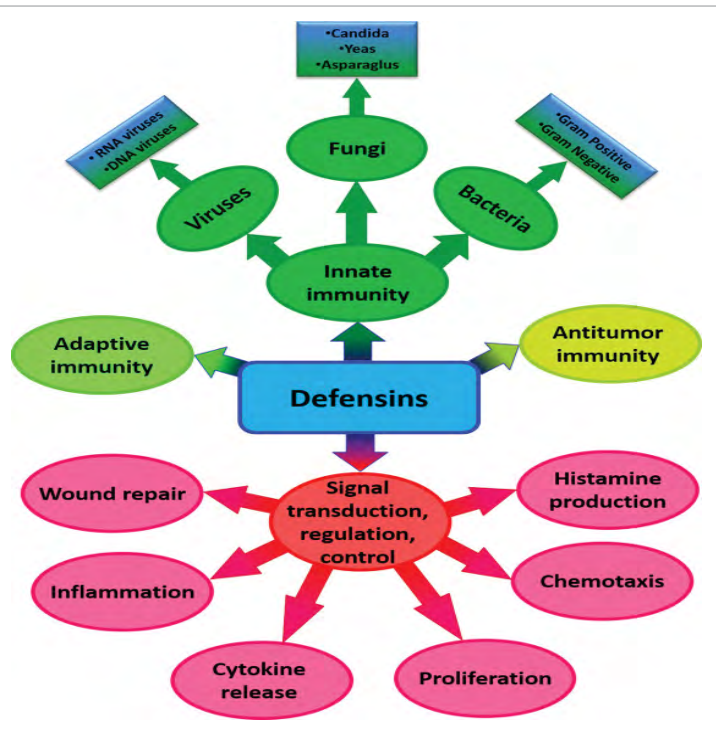

Figure 4: Roles of $\beta$-defensins. 


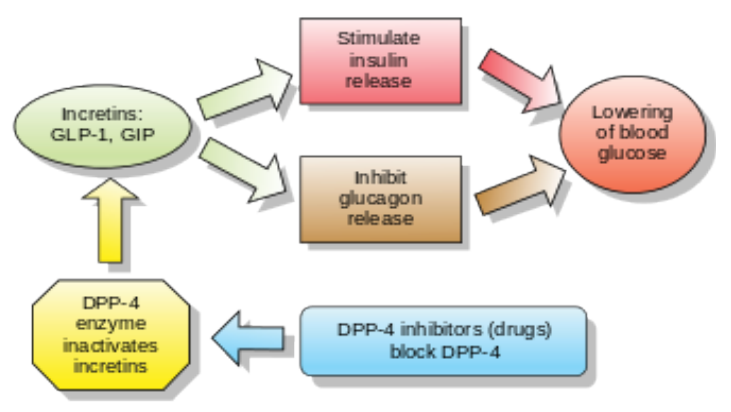

Figure 5: GLP-1 and diabetes.

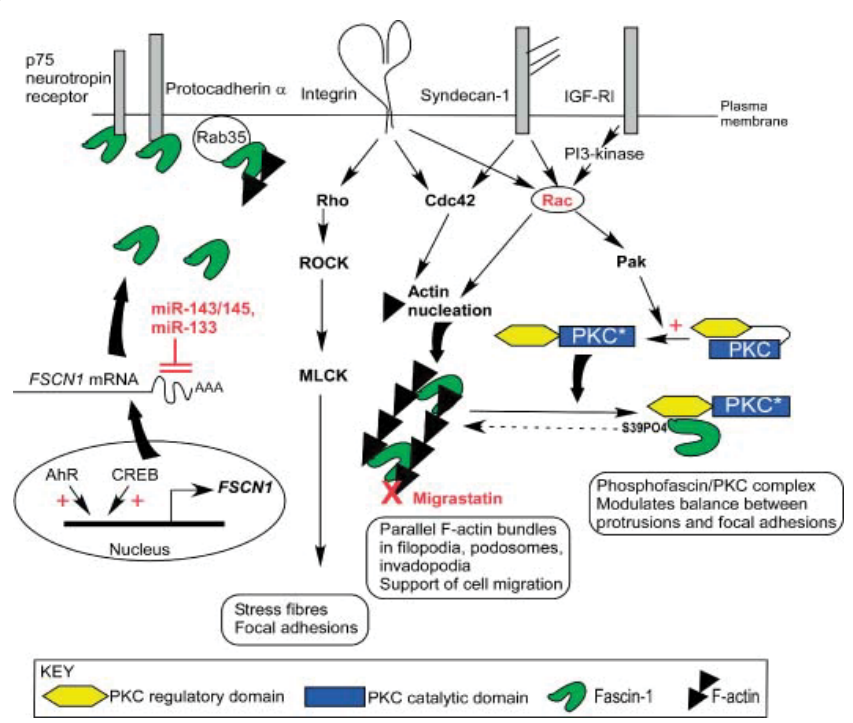

Figure 6: Cellular pathways that regulate fascin-1 transcript and protein.

and malignant progression of breast cancer. Modulation of the ER function might be a promising tool with which to control breast cancer. In fact, anti-estrogens are widely used for its therapy. The expression of ERa is closely associated with breast cancer biology, especially the development of tumors; for example, breast carcinomas which lack ERa expression often reveal more aggressive phenotypes. On the other hand, another ER, ER $\beta$, was recently identified. Subsequently, numerous studies have reported on the expression of ER $\beta$ in various cancers, including our observations in breast, lung, and stomach. Immunohisto-chemical studies suggest that ER $\beta$ tends to be expressed in ER $\alpha$ positive breast cancers (Figure 7), and that there are ER $\alpha$ and ER $\beta$ coexpressing cells in human breast cancer. Furthermore, the existence of various variant forms of ER $\beta$ has been reported in breast cancer cells [18].

\section{Beta-1-Adrenergic Receptor $\left(\beta_{1}-\mathrm{AR}\right)$ blockers}

Beta-1-adrenergic receptor $\left(\beta_{1}-\mathrm{AR}\right)$ blockers not only reduce the incidence of sudden death but also reduce the ventricular volume in heart failure. In vitro, the Gly389 variant of $\beta_{1}$-AR mediates less adenylyl cyclase activities than the Arg389 variant (Figure 8), so Arg389Gly polymorphism was investigated with regard to the genesis, progression, or arrhythmogenesis of dilated cardiomyopathy (DCM). In conclusion, this is the first study to demonstrate that the Gly389 allele of the $\beta_{1}$-AR gene suppressed the occurrence of VT in patients with DCM, suggesting the possibility that it deliberates a decreased risk of sudden death [19]. Similarly, the beta-2 adrenergic receptor $\left(\beta_{2} A R\right)$

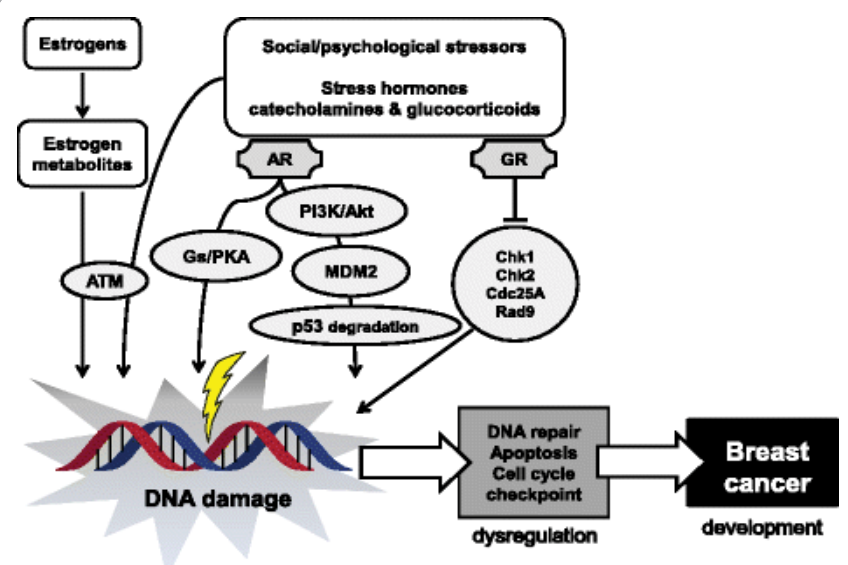

Figure 7: Role of ER in breast cancer.

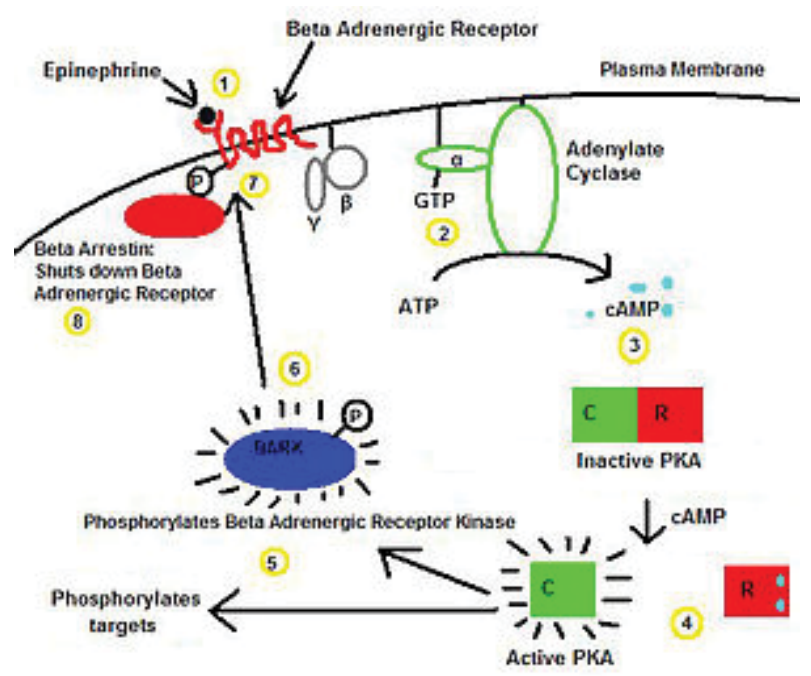

Figure 8: Beta adrenergic receptor kinase activation pathway.

has involved in the pathogenesis of hypertension, both on the basis of studies suggesting altered $\beta_{2}$ mediated vasodilatation and on the basis of molecular genetics association. Recently, a relationship between the Arg160Gly polymorphism in the $\beta_{2} \mathrm{AR}$ gene and hypertension in an African-Caribbean population was observed. It was found that the Gly16 allele was more common in hypertensive subjects than in normotensive African-Caribbean controls. Because the Gly16 allele directs an increased propensity for depressed regulation of the receptor, there is a possibility that an impaired vasodilatation in peripheral arteries in response to $\beta_{2} A R$ agonists may play a role in the hypertension of individuals carrying the Gly16 allele [20].

\section{$\beta$-thromboglobulins}

One of the earliest events during host defense is the recruitment of neutrophil granulocytes to sites of tissue injury. Several chemotactic cytokines belonging to the CXC subfamily of chemokines are thought to be implicated in this kind of response. Especially those CXC chemokines that are stored in blood platelets and become immediately released upon activation are likely to dominate neutrophil-dependent host defense at the on-set of inflammation. The major platelet-derived CXC chemokines are the $\beta$-thromboglobulins (Figure 9) and platelet factor 4 (PF-4), which are both released into the blood at micro molar concentrations. The collective term " $\beta$-thromboglobulins" stands 


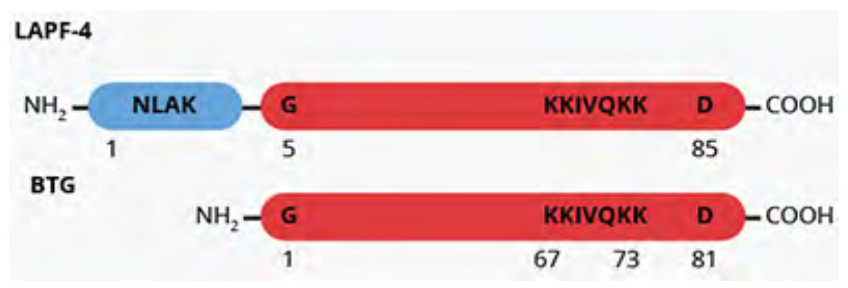

Figure 9: Domain structure of $\beta$-thromboglobulins.

for a group of homologous and immunologically cross-reactive platelet a granule-derived protein, which only differ in the length of their amino-termini, Mainly two variants have been identified in human platelets [21].

\section{$\beta$-alanine}

$\beta$-alanine (a beta-amino corrosive) has gotten recent interest because of its potential impacts on muscle $\mathrm{pH}$ and exercise execution when stacked more than a few weeks. $\beta$-alanine (Figure 10) is the rate constraining component for carnosine production, a noteworthy $\mathrm{H}^{+}$cushion found inside muscle fibers $(\mathrm{pKa}=6.83)$. Higher musclecarnosine fixation may likewise profit practice execution with its cell reinforcement properties [22] and by increasing the calcium affectability of muscle filaments and calcium discharge channels $[23,24]$ and upgrading vessel vasodilatory impacts [25].

\section{Carnosine}

Carnosine (Figure 11) is a dipeptide along with a very high amount in mammalian skeletal muscle. It is manufactured by carnosine synthetase from the amino acids L-histidine and $\beta$-alanine, of which the second is the rate-limiting precursor, and despoiled by carnosinase. Recent researches have exposed that the chronic oral ingestion of $\beta$-alanine can significantly (up to $80 \%$ ) raise the carnosine content of human skeletal muscle. Remarkably, muscle carnosine filling leads to enhanced performance in high-intensity workout in both untrained and trained individuals. Although carnosine is not involved in the classic ATP-generating metabolic pathways, this suggests an important role of the dipeptide in the homeostasis of contracting muscle cells, especially during high rates of anaerobic energy delivery. Carnosine can offset acidosis by acting as a pH buffer, but improved contractile performance may also be obtained by enhanced excitation-contraction coupling and defence against reactive oxygen species [26-31]. Betaalanine is rapidly rising as a popular ergogenic nutritional increment for athletes worldwide, and the currently accessible scientific prose proposes that its practice is evidence-based. However, many aspects of the increment, such as the potential side-effects and the mechanism of action, entail additional and thorough analysis by the sports science community [32-34].

\section{$\beta$-glucans}

$\beta$-Glucans are polysaccharides of D-glucose monomers linked through $\beta$-glycosidic bonds. As a variety of dietary fiber (DF), $\beta$-glucan can be established in a collection of common sources, for example; mushrooms, green growth, yeast, microscopic organisms, oat and grain [35]. Due to their interesting somatic and biological properties, $\beta$-Glucan displays a broad spectrum of biological actions including immune-modulating (Figure 12), anti-tumor, anti-inflammatory properties, and anti-aging [36].

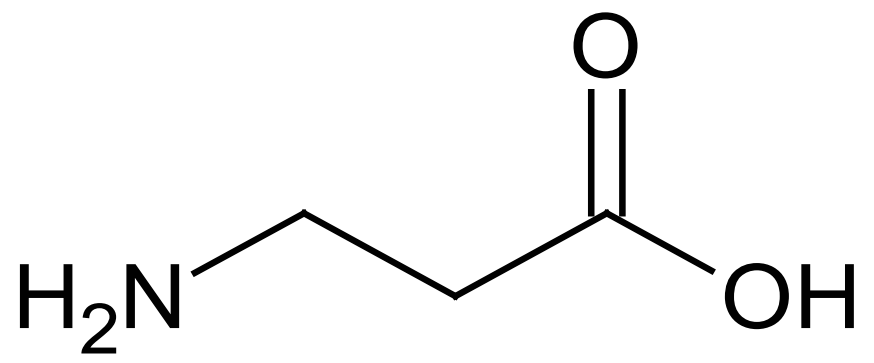

Figure 10: $\beta$-alanine.

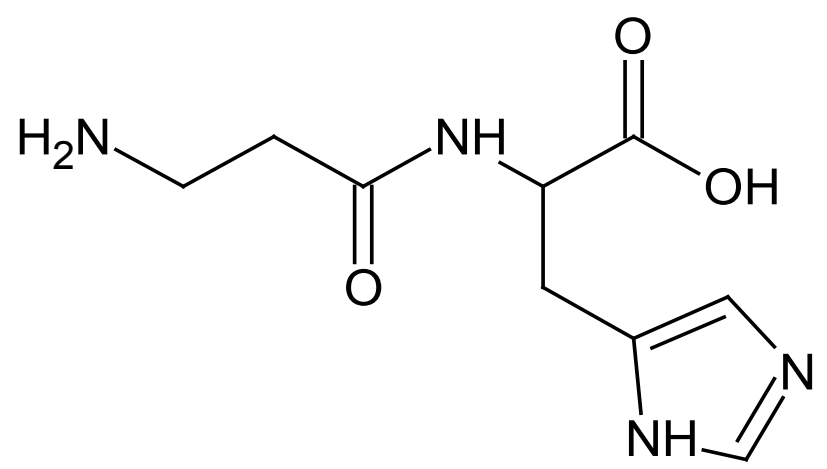

Figure 11: Carnosine.

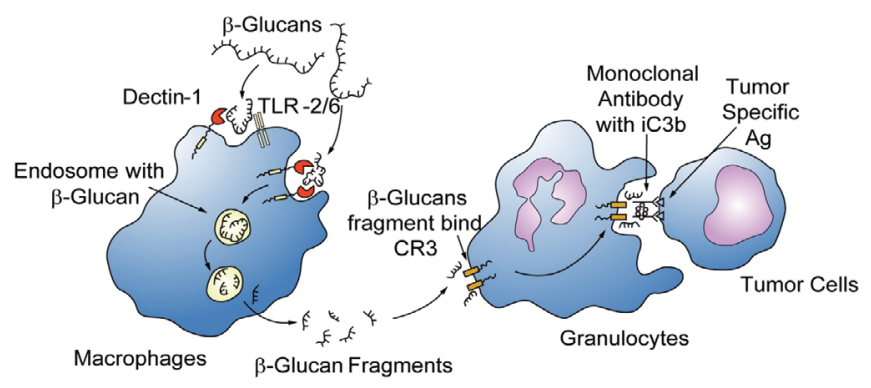

Figure 12: The effects of $\beta$-glucan on human immune.

\section{$\beta$-Lactam}

$\beta$-Lactam or azetidin-2-one is a significant structural motif of the penicillin, cephalosporin, carbapenem, and carbecephem types of antibiotics [37]. Naturally arising as well as artificial monobactams, such as nocardicins and tabtoxin, are also recognized for their exclusive antibacterial activities. Cispentacin exhibits a strong antifungal in vitro activity against various Candida strains, e.g., Candida albicans, Candida krusei and Candida utilis. It revealed its weakness in vitro activity against Trichophyton mentagrophytes, while not in vitro activity was observed against Cryptococcus and Aspergillus species [38-40]. Sitagliptin phosphate (Januvia ${ }^{\mathrm{TM}}$ ) was the first permitted drug to switch the blood glucose concentration [41]. Sitagliptin comprises an (R)-3-amino-4-(2,4,5-trifluorophenyl) butanoic acid subunit [42]. Many further derivatives of sitagliptin have been synthetized and tested as potential antidiuretic drugs (Figure 13) [43].

\section{Vitronectin receptor}

The integrin receptor $\alpha_{v} \beta_{3}$ "vitronectin receptor" (a hetrodimeric protein) is a fascinating therapeutic target in the treatment of osteoporosis, restenosis, cancer growth and metastasis. Derivatives of (R)-3amino-3-(3,5 dichlorophenyl) propanoic acid and (S)-3-amino- 


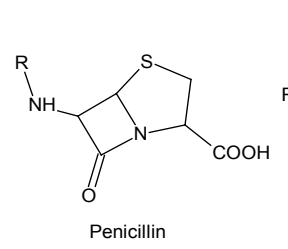<smiles>[R]NC1C(=O)N2C(C(=O)O)=C(C(=O)O)CS[C@H]12</smiles><smiles>[R]C1C(=O)N2C(C(=O)O)=C(P)CC12</smiles>

Carbapenem<smiles>NC1CCCC1C(=O)O</smiles>

Cispentacin
Cephalosporin<smiles>O=N[C@@H](CC(=O)Nc1cc(F)c(F)cc1F)N1CCn2c(Cl)nnc2C1</smiles>

Sitagliptin Phosphate (Januvia)

Figure 13: Different antibiotics.

3-(3-pyridyl) propanoic acid have experienced as integrin receptor antagonists $[44,45]$. Elarofiban (RWJ-53308) is a fibrinogen receptor antagonist along with an antithrombotic effect [46]. It holds an (S)3-amino-3-(3-pyridyl) propanoic acid subunit. Derivatives of (R)-3amino-3-phenylpropanoic acid, (R)-3-amino-3-(3-pyridyl) propanoic acid and (R)-3-amino-5-phenylpentanoic acid have been tested as hepatitis $\mathrm{C}$ virus (HCV) NS5B polymerase inhibitors, a valid target for antiviral therapy against $\mathrm{HCV}[47,48]$. (R)-3-amino-3-phenylpropanoic acid and (R)-3-amino-3-benzo $(1,3)$ dioxol-5yl propanoic acid have introduced into anti-inflammatory bradykinin B1 receptor (protein coupled receptor) antagonists [49,50]. Another $\beta$-amino acid, (R)-3amino-3-(3-fluorophenyl) propanoic acid, has also been utilized in the production of antagonists of chemokine receptors, anti-inflammatory agents [51]. Furthermore, several $\beta$-aryl, $\beta$-heteroaryl and $\beta$-arylalkyl$\beta$-amino acid enantiomers have experienced as constituents of anticancer agents [52,53].

\section{Conclusion}

From this discussion it has been concluded that $\beta$-amino acids and derivatives have potential therapeutic values on account of bearing varieties of biological activities including antifungal, antitubercular, antibacterial and anticancer. They are also used in the treatment of many diseases and health issues. $\beta$-amino acids gained significant interest due to their interesting pharmaceutical uses as hypoglycemic, antiketogenic characteristics, sterile and antifungal activities, anthelminthic as well as potent insecticidal characteristics. These are vital building blocks for the preparation of pharmaceutical and agrochemical target molecules. These are utilized in development of drugs, bimolecular structure and molecular recognition. They are also important in treatment of different diseases which are viral to human health. They play important role in regulation of nutritional metabolism and immunity. It has also led to their wider adoption as intermediates in new drugs and has been a focus of considerable attention in medicinal chemistry. $\beta$-Amino acids have found extensive applications as components of biologically active peptides and small molecule pharmaceuticals. Synthetic derivatives of biologically relevant peptides incorporating $\beta$-amino acids often display interesting pharmacological activity, with increased potency and enzymatic stability. $\beta$-peptides participate in arrangement of incredible stable auxiliary structures. No doubt, the growing interest in $\beta$-amino acids will prove to be a great challenge and stimulate new and improved methods for the synthesis of their biological active derivatives in near future.

\section{References}

1. Shinagawa S, Kanamaru T, Harada S, Asai M, Okazaki H (1987) Chemistry of emeriamine and its analogs and their inhibitory activity in long-chain fatty acid oxidation. J Med Chem 30: 1458-1463.

2. Kanamaru T, Shinagawa S, Asai M, Okazaki H, Sugiyama Y, et al. (1985) Life Sci 37: 217-223.

3. Seebach D, Matthews JL (1997) $\beta$-Peptides: a surprise at every turn. Chem Commun, pp: 2015-2022.

4. Namikoshi M, Rinehart KL, Dahlem AM, Beasley VR, Carmichael WW (1989) Total synthesis of Adda, the unique C 20 amino acid of cyanobacterial hepatotoxins. Tetrahedron Lett 30: 4349-4352.

5. Crews P, Manes LV, Boehler M, Jaspis SP (1986) Jasplakinolide, a cyclodepsipeptide from the marine sponge, Jaspis $\mathrm{sp}$. Tetrahedron Lett 27 : 2797-2800.

6. Sibi MP, Manyem S (2000) Tetrahedron 56: 8033.

7. Porter EA, Weisblum B, Gellman SH (2002) Mimicry of host-defense peptides by unnatural oligomers: antimicrobial $\beta$-peptides. J Am Chem Soc 124: 73247330.

8. Beke T, Somlai C, Perczel A (2006) Toward a rational design of $\beta$-peptide structures. J Comput Chem 27: 20-38.

9. Wu G, Bazer FW, Davis TA, Jaeger LA, Johnson GA, et al. (2007) Important roles for the arginine family of amino acids in swine nutrition and production - $A$ Review. Livestock Science 112: 8-22.

10. Fazal-ur-Rehman M, Nagina NR (2017) Biological Applications of $\beta$-amino acids and its derivatives. International Academy of Engineering and Medical Research. Vol. 2.

11. Adel RA, Ali MG, Abdulhakeem AA, Abdulaziz AA (2004) Clinic Experi Pharma Phys 31: 167-172.

12. Gressner AM, Heinleu BK, Dooley S (2002) J Front Biosci 7: 793-807.

13. Deaue R, Yau SD, Submamaryan RK, Larue B (2003) J Nat Med 7: 907-913.

14. Olsson A, Csajbok L, Ost M, Hoglund K (2004) Marked increase of ß-amyloid $(1-42)$ and amyloid precursor protein in ventricular cerebrospinal fluid after severe traumatic brain injury. J Neurol 251: 870-876.

15. Yu PL (2004) Avian antimicrobial peptides: the defense role of $\beta$-defensins. $J$ Biochem Biophys Res Commun 323: 721-727.

16. Kim D, Wang L, Baconi M, Eiermann JG (2005) (2R)-4-Oxo-4-[3(Trifluoromethyl)-5,6-dihydro[1,2,4]triazolo[4,3-a]pyrazin- $\quad 7(8 \mathrm{H})-y \mathrm{ll}]-1-(2,4,5-$ trifluorophenyl)butan-2-amine: A Potent, Orally Active Dipeptidyl Peptidase IV Inhibitor for the Treatment of Type 2 Diabetes. J Med Chem 48: 141-151.

17. Hashimoto Y, Skacel M, Adams J (2005) Roles of fascin in human carcinoma motility and signaling: prospects for a novel biomarker? Int. J. Biochem Cell Biol 37: 1787-1804.

18. Hayashi SI, Eguchi H, Tanimoto K, Yoshida T, Omoto Y, et al. (2003) The expression and function of estrogen receptor alpha and beta in human breast cancer and its clinical application. Endocr. Relat. Cancer 10: 193-202.

19. Iwai C, Akita H, Shiga N (2002) Suppressive Effect of the Gly389 Allele of the B1-Adrenergic Receptor Gene on the Occurrence of Ventricular Tachycardia in Dilated Cardiomyopathy. Circulation. J 66: 723-728.

20. Kotanko P, Binder A, Tasker J, DeFreitas P, Kamdar S, et al. (1997) Essential hypertension in African Caribbeans associates with a variant of the $\beta 2$ adrenoceptor. Hypertension 30: 773-776.

21. Brandt E, Petersen F, Ludwig A (2000) The beta-thromboglobulins and platelet factor 4: blood platelet-derived CXC chemokines with divergent roles in early neutrophil regulation. J. Leukoc. Biol. 67: 471.

22. Kohen R, Yamamoto Y, Cundy KC, Ames BN (1988) Antioxidant activity of carnosine, homocarnosine, and anserine present in muscle and brain Proceedings of the National Academy of Sciences of the United States of America 85: 3175-3179.

23. Dutka TL, Lamb GD (2004) Effect of carnosine on excitation-contraction coupling in mechanically-skinned rat skeletal muscle. Journal of Muscle Research and Cell Motility 25: 203-213.

24. Dutka TL, Lamboley CR, McKenna MJ, Murphy RM, Lamb GD (2012) Effects of carnosine on contractile apparatus $\mathrm{Ca2+-sensitivity} \mathrm{and} \mathrm{sarcoplasmic}$ reticulum $\mathrm{Ca} 2+$ release in human skeletal muscle fibers. Journal of Applied Physiology 112: 728-736.

25. Ririe DG, Roberts PR, Shouse MN, Zaloga GP (2000) Vasodilatory actions of the dietary peptide carnosine. Nutrition (Burbank, Los Angeles County, Calif.) 16: 168-172. 
Citation: Riaz NN, Rehman F, Ahmad MM (2017) B-Amino Acids: Role in Human Biology and Medicinal Chemistry - A Review. Med Chem 7: $302-307$. doi: $10.4172 / 2161-0444.1000472$

26. Baguet A, Reyngoudt H, Pottier A, Everaert I, Callens S, et al. (2009) Carnosine loading and washout in human skeletal muscles. Journal of Applied Physiology 106: 837-842.

27. Derave W, Özdemir MS, Harris RC, Pottier A, Reyngoudt H, et al. (2007) $\beta$-alanine supplementation augments muscle carnosine content and attenuates fatigue during repeated isokinetic contraction bouts in trained sprinters. Journal of Applied Physiology 103: 1736-1743.

28. Abe H (2000) Role of histidine-related compounds as intracellular proton buffering constituents in vertebrate muscle. Biochemistry (Moscow) 65: 757-765.

29. Suzuki Y, Ito O, Mukai N, Takahashi H, Takamatsu K (2002) High level of skeletal muscle carnosine contributes to the latter half of exercise performance during 30-s maximal cycle ergometer sprinting. Japanese Journal of Physiology 52: $199-205$

30. Suzuki Y, Ito O, Takahashi H, Takamatsu K (2004) The effect of sprint training on skeletal muscle carnosine in humans. International Journal of Sport and Health Science 2: 105-110.

31. Baguet A, Bourgois J, Vahnee L, Achten E, Derave W (2010) Important role of muscle carnosine in rowing performance. Journal of Applied Physiology 109: 1096-1101.

32. Harris RC, Tallon MJ, Dunnett M, Boobis L, Coakley J, et al. (2006) The absorption of orally supplied beta-alanine and its effect on muscle carnosine synthesis in human vastus lateralis. Amino Acids 30: 279-289.

33. Hill CA, Harris RC, Kim HJ, Harris BD, Sale C, et al. (2007) Influence of betaalanine supplementation on skeletal muscle carnosine concentrations and high intensity cycling capacity. Amino Acids 32 : 225-233.

34. Boldyrev AA (2007) Carnosine and oxidative stress in cells and tissues. New York: Nova Science Publishers.

35. Abernathy RL, Teal PEA, Meredith JA, Nachman RJ (1996) Induction of pheromone production in a moth by topical application of a pseudopeptide mimic of a pheromonotropic neuropeptide. Proc Natl Acad Sci USA 93: 12621-12625.

36. Altstein M (2004) Role of neuropeptides in sex pheromone production in moths. Peptides 25: 1491-1501.

37. Georg GI (1992) The Organic Chemistry of b-Lactams. VCH: New York, NY and References cited therein.

38. Aoki H, Sakai H, Kohsaka M, Konomi T, Hosoda JJ (1976)Antibiot 29: 890e901.

39. Hashimoto M, Komori T, Kamiya T (1976) J Am Chem Soc 98: 3023e3025.

40. Imada A, Kitano K, Kintaka K, Muroi M, Asai M (1981) Nature 289: 590e591.
41. Cardillo G, Tomasini C (1996) Asymmetric synthesis of $ß$-amino acids and $\alpha$-substituted $\beta$-amino acids. Chem. Soc. Rev. 25: 117-128.

42. Havale SH, Pal M (2009) Medicinal chemistry approaches to the inhibition of dipeptidyl peptidase- 4 for the treatment of type 2 diabetes. Bioorg. Med. Chem. 17: $1783-1802$.

43. Thornberry NA, Weber AE (2007) Discovery of JANUVIA ${ }^{T M}$ (Sitagliptin), a Selective Dipeptidyl Peptidase IV Inhibitor for the Treatment of Type2 Diabetes. Curr. Top. Med. Chem. 7: 557-568.

44. Xu J, Ok HO, Gonzalez EJ, Habulihaz B, Leiting B, et al. (2004) Discovery of potent and selective $\beta$-homophenylalanine based dipeptidyl peptidase IV inhibitors. Bioorg. Med. Chem. Lett. 14: 4759-4762.

45. Meissner RS, Perkins JJ, Duong LT, Hartman GD, Hoffman WF, et al. (2002) Nonpeptide $\alpha \vee \beta 3$ antagonists. Part 2: constrained glycyl amides derived from the RGD tripeptide. Bioorg. Med. Chem. Lett. 12: 25-29.

46. Nagarajan SR, Rogers TE, Marrufo LD, Collins JT, Kleine HP, et al. (2007) R-isomers of Arg-Gly-Asp (RGD) mimics as potent $\alpha \vee \beta 3$ inhibitors. Bioorg. Med. Chem. 15: 3783-3800.

47. Hoekstra WJ, Maryanoff BE, Damiano BP, Cohen JH, Costanzo MJ, et al (1999) Potent, orally active GPIIb/llla antagonists containing a nipecotic acid subunit. Structure-activity studies leading to the discovery of RWJ-53308. J. Med. Chem. 42: 5254-5265.

48. Yan S, Larson G, Wu JZ, Appleby T, Ding Y, et al. (2007) Novel thiazolones as HCV NS5B polymerase allosteric inhibitors: Further designs, SAR, and X-ray complex structure. Bioorg. Med. Chem. Lett. 17: 63-67.

49. Bachand C, Belema M, Deon DH, Good AC, Goodrich J, et al. (2008) US Patent 0044379.

50. Human J, Fotsch C, Chen JJ, Biswas K, Riahi B, et al. (2007) Identification of a nonpeptidic and conformationally restricted bradykinin B1 receptor antagonist with anti-inflammatory activity. J. Med. Chem. 50: 607-610.

51. Gougat J, Ferrari B, Sarran L, Planchenault C, Poncelet M, et al. (2004) SSR240612, a new non-peptide antagonist of the bradykinin B1 receptor Biochemical and pharmacological characterization. J. Pharm. Exp. Ther. 309: 661-669.

52. Basford PA, Stephenson PT, Taylor SCJ, Wood A (2003) World Patent WO 2003084954.

53. Georg GI, Harriman GCB, Hepperle M, Clowers JS, Vander Velde DG (1996) Synthesis, conformational analysis, and biological evaluation of heteroaromatic taxanes. J. Org. Chem. 61: 2664-2676. 